\title{
A new bernissartiid crocodyliform from the Lower Cretaceous Wessex Formation (Wealden Group, Barremian) of the Isle of Wight, southern England
}

Steven C. Sweetman, Ulysse Pedreira-Segade, and Steven Vidovic

Acta Palaeontologica Polonica 60 (2), 2015: 257-268 doi:http://dx.doi.org/10.4202/app.00038.2013

A substantially complete skull of a small crocodyliform recently found on the foreshore near Yaverland on the south-east coast of the Isle of Wight, southern England is described. The locality, mode of preservation and associated matrix indicate that it is derived from one of the plant debris beds of the Lower Cretaceous Wessex Formation (Barremian, Wealden Group). The dentition, unique among crocodyliforms, serves to confirm that the specimen is referable to the, until now, monotypic family Bernissartiidae. Apomorphies, including placement of the choana entirely within the pterygoids and disposition of cranial sutures demonstrate that the Isle of Wight skull cannot be referred to Bernissartia fagesii, known from contemporaneous strata. Furthermore, these characters indicate that the specimen should not be referred to a new species of Bernissartia. It is therefore placed in a new genus and species, Koumpiodontosuchus aprosdokiti. The systematic position of Bernissartiidae, and characters used to diagnose Eusuchia, including placement of the choana(e) within the prerygoids, are discussed. Until recently this condition was thought to be restricted to Eusuchia with all non-eusuchian neosuchian crorocdiliforms possessing choanae bounded posteriorly by the pterygoids and anteriorly by the palatines. While the choana of Koumpiodontosuchus aprosdokiti gen. et sp. nov. is entirely bounded by the pterygoids it differs from the choanae of eusuchians in lacking a median septum, being anteroposteriorly elongate and in its anterior placement.

Key words: Crocodyliformes, Eusuchia, Neosuchia, Bernissartiidae, Cretaceous, Barremian, Wealden, England.

Steven C. Sweetman [steven.sweetman@port.ac.uk] and Steven U. Vidovic [steven.vidovic@port.ac.uk ], Palaeobiology Research Group, School of Earth and Environmental Sciences, University of Portsmouth, Burnaby Building, Burnaby Road, Portsmouth, PO1 3QL, United Kingdom; Ulysse Pedreira-Segade [ulysse.pedreirasegade@ens-lyon.fr], Departement des Sciences de la Terre, Universite Claude Bernard Lyon 1 et Ecole Normale Superieure de Lyon, 2 rue Dubois, 69622 Villeurbanne cedex, France. 
This is an open-access article distributed under the terms of the Creative Commons Attribution License (for details please see creativecommons.org), which permits unrestricted use, distribution, and reproduction in any medium, provided the original author and source are credited.

FarF Full text $(542.8 \mathrm{kB})$ ।

FoF 5 Supplementary file $(870.4 \mathrm{kB})$ 